\title{
MicroRNAs participate in the murine oligodendroglial response to perinatal hypoxia-ischemia
}

\author{
Derin Birch', Blair C. Britt' ${ }^{1}$, Silena C. Dukes ${ }^{2}$, John A. Kessler' and Maria L.V. Dizon ${ }^{2}$
}

\begin{abstract}
BACKGROUND: Hypoxic-ischemic injury $(H \mathrm{H})$ to preterm brain results in white matter loss. The endogenous oligodendroglial response to perinatal $\mathrm{HI}$ is characterized by increased oligodendroglial progenitor cells (OPCs). MicroRNAs (miRs) are important post-transcriptional regulators of gene expression, and a few miRs have been shown to regulate differentiation of OPCs into mature oligodendroglia. We tested the hypothesis that miRs play a role in the increase in OPCs in response to perinatal $\mathrm{HI}$.
\end{abstract}

METHODS: We inducibly deleted the miR-processing enzyme Dicer in OPCs using a tamoxifen-inducible NG2CreER ${ }^{T 2}$ transgene in Dicer ${ }^{\mathrm{r} / \mathrm{fl}}$ mice. After $\mathrm{HI}$, mice were analyzed for OPC differentiation using immunofluorescence and for white matter formation by Luxol fast blue (LFB) staining. Functional recovery from injury was investigated using digital gait analysis. We also tested whether $\mathrm{HI}$ changed miRs known to regulate OPC differentiation using quantitative RT-PCR.

RESULTS: Perinatal HI induced significant increases in miR138 and miR-338, two miRs known to regulate OPC differentiation. Knockdown of Dicer increased myelin basic protein and LFB staining within the corpus callosum after HI. In addition, there was significant improvement in motor function 14 and $24 \mathrm{~d}$ post lesion.

CONCLUSION: Changes in specific mature miRs expressed in OPCs following HI may contribute to white matter injury.

$\mathbf{P}$ reterm babies are at particular risk for white matter injury due to hypoxia-ischemia (HI). This is likely because oligodendrocyte progenitor cells (OPCs) that are abundant at the time of preterm birth are particularly vulnerable to this type of injury (1). Nonetheless, HI results in an increase in OPCs yet a decrease in mature oligodendrocytes (OLs) and myelin $(2,3)$. This is thought to be caused by the inability of new OPCs to differentiate into mature OLs (3). Little is known about the mechanism leading to this arrest in OPC differentiation.

MicroRNAs (miRs) are small noncoding RNAs that are important post-transcriptional regulators of gene expression (4) that were first identified as regulators of developmental transitions, functioning to deplete mRNAs left over from an earlier developmental stage (5). MiRs are particularly enriched in the brain where they function in neural stem/progenitor cell development $(6,7)$. MiRs are sequentially processed, progressing from a primary form to a premature form with a stemloop structure and finally to the mature form that suppresses protein translation by binding to the $3^{\prime} \mathrm{UTR}$ of mRNA to either inhibit translation or augment degradation. Progression from the premature form to the mature form requires the ribonuclease Dicer $(4,7)$. Conditional loss of Dicer has demonstrated the critical role for miRs in many mouse tissues.

MiRs have been demonstrated to be important for normal central nervous system myelination as evidenced by delayed myelination in Olig2Cre;Dicer ${ }^{\mathrm{f} / \mathrm{l}}$ and CNPase;Dicer ${ }^{\mathrm{n} / \mathrm{l} l}$ mice (8), decreased myelin in Olig1Cre;Dicer ${ }^{\mathrm{f} / \mathrm{f}}$ mice (9), and dysmyelination in PLPCre;Dicer ${ }^{\mathrm{f} / \mathrm{fl}}$ mice (10). To test the hypothesis that miRs are involved in the oligodendroglial lineage response to perinatal $\mathrm{HI}$, we established a mutant mouse strain in which Dicer can be inducibly excised from NG2 cells $\left(\mathrm{NG}_{2} \mathrm{CreER}^{\mathrm{T} 2} ; \mathrm{Dicer}^{\mathrm{f} / \mathrm{ll}}\right.$ mice), neural progenitors that are distributed widely throughout the brain and that differentiate predominantly into OPCs (11).

\section{RESULTS}

Knockdown of Dicer in Neural Progenitors Following Perinatal Hypoxia-Ischemia Increases Mature Oligodendrocytes and White Matter Within the Corpus Callosum

To inducibly excise the Dicer 1 intron within NG2+ progenitor cells, tamoxifen was administered to NG2CreER ${ }^{\mathrm{T} 2}$; Dicer $^{\mathrm{f} / / \mathrm{l}}$ mice immediately after recovery from $\mathrm{HI}$ and daily thereafter for a total of $4 \mathrm{~d}$ (P7, P8, P9, and P10). Mice were killed $28 \mathrm{~d}$ post lesion $(\mathrm{dpl})$ when we used immunofluorescence to probe for markers of differentiated OLs. We compared the following two groups: HI/vehicle-treated (LesVeh) and HI/tamoxifentreated (LesTam). We assayed for changes in expression of myelin basic protein (MBP), a marker of mature myelinating $\mathrm{OL}$, within the corpus callosum. We compared protein expression by relative fluorescence and found a significant 1.46 -fold increased expression of MBP in the corpus callosum of the LesTam group compared with the LesVeh group (LesTam $5.30 \pm 0.2$ average intensity vs. LesVeh $3.63 \pm 0.5$ average intensity, $P=0.048 ; n=4$ LesVeh and 4 LesTam mice) (Figure 1a-c). We also assayed for changes in expression of CNPase, a 

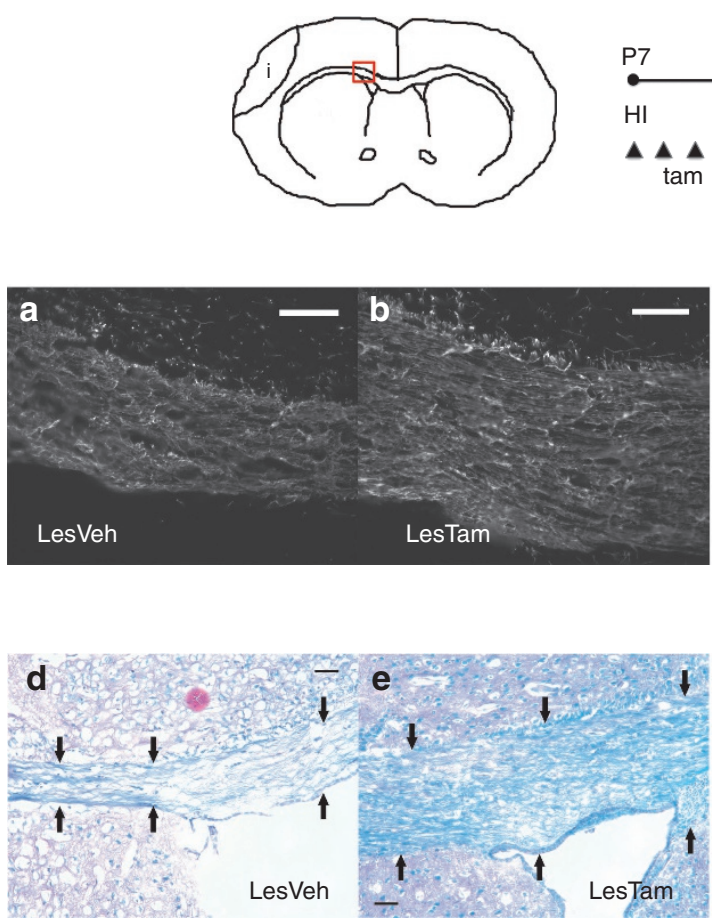

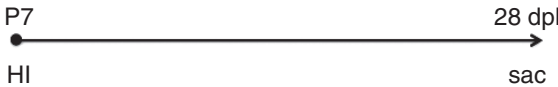

$\boldsymbol{\Delta} \underset{\operatorname{tam}}{\boldsymbol{\Delta}} \boldsymbol{\Delta}$

C

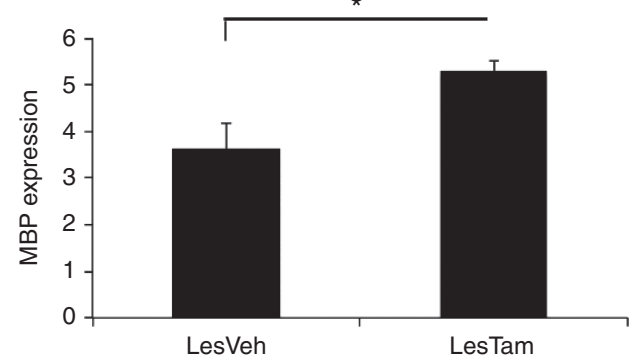

f

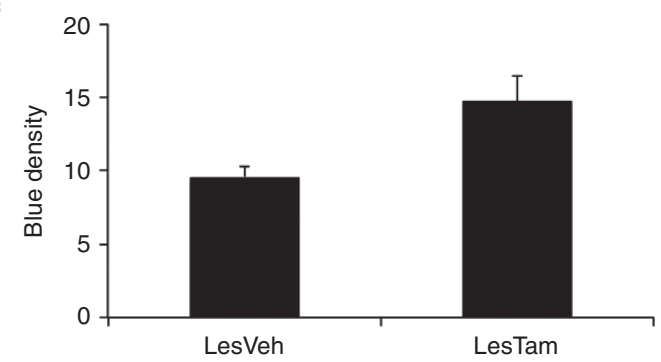

Figure 1. Loss of Dicer in NG2 expressing cells following hypoxia-ischemia results in increased mature oligodendrocytes and improved myelin. Schematic of injury area and timeline of experimental procedure (i, infarct area; P, postnatal day; dpl, days post lesion; $\mathrm{HI}$, hypoxia-ischemia; sac, sacrifice; tam, tamoxifen). The red box denotes area of corpus callosum imaged on coronal sections. Representative micrographs of myelin basic protein (MBP) staining within the corpus callosum of (a) a lesioned mouse treated with vehicle (LesVeh) (magnification: $\times 40$; scale bar $=25 \mu \mathrm{m}$ ) and (b) a lesioned mouse treated with tamoxifen (LesTam) (magnification: $\times 40$; scale bar $=25 \mu \mathrm{m}$ ). (c) Quantification of MBP expression within corpus callosum. Error bars represent SEM. ${ }^{*} P=0.048 ; n=4$ LesVeh and 4 LesTam. (d) Representative micrograph of Luxol fast blue (LFB) staining within the corpus callosum of a lesioned mouse treated with vehicle (LesVeh) (magnification: $\times 20$; scale bar $=25 \mu \mathrm{m}$ ). Black arrows indicate edge of corpus callosum. (e) Representative micrograph of Luxol fast blue (LFB) staining within the corpus callosum of a lesioned mouse treated with tamoxifen (LesTam) (magnification: $\times 20$; scale bar $=25 \mu \mathrm{m}$ ). (f) Quantification of LFB expression within corpus callosum; error bars represent SEM. $n=5$ LesVeh and 4 LesTam.

marker that is expressed by immature OL. However, we found only a 1.29 -fold trend towards increased expression that did not reach significance. To further substantiate an increase in mature myelinating OLs, we performed histologic stains for myelin using Luxol fast blue (LFB) on sections collected at $28 \mathrm{dpl}$. We found qualitatively improved myelin staining in the LesTam group compared with the LesVeh group (Figure 1d,e). Quantification of blue density demonstrated a 1.54-fold increase in the LesTam group compared with the LesVeh group that did not reach significance (Figure 1f). These findings support the hypothesis that miRs regulated by Dicer in neural progenitors antagonize the formation of OLs after perinatal HI.

To explore whether the increase in mature myelinating OL results from an increased total number of oligodendroglia, we used immunofluorescence to probe for Olig1, a transcription factor expressed by cells along the continuum of the oligodendroglial lineage, from OPCs to mature OLs. Following the same induction protocol, mice were killed $7 \mathrm{dpl}$ and we assayed for changes in the number of Olig1+ cells within the corpus callosum comparing lesioned mice after tamoxifen treatment with lesioned mice that received vehicle; we found no change in Olig1+ cells between treatment groups. Next, we probed for Olig2, a transcription factor that is expressed by neural progenitors and OPCs, comparing the same groups at the same time points. Interestingly, we observed a 0.38 -fold trend towards decreased numbers of Olig2+ cells that did not reach significance due to variance (Supplementary Figure S1a online). Conversely, when we probed for PDGFRA, a growth factor receptor that marks OPCs, we observed a 1.90 -fold trend towards increased numbers of PDGFRA+ cells that did not reach significance due to variance (Supplementary Figure S1b online). These findings indicate that excision of Dicer did not alter the total number of cells in the OL lineage and suggest that miRs may regulate the commitment of neural progenitor cells to OPCs.

\section{Knockdown of Dicer in Neural Progenitors Following Perinatal Hypoxia-Ischemia Improves Ambulation}

Since we observed an increase in myelinating OLs after excision of Dicer, we used digital gait analysis to assess ambulation, comparing sham-injury mice that received vehicle (ShamVeh) with sham-injury mice that received tamoxifen (ShamTam), LesTam mice, and LesVeh mice. We assayed mice walking at a speed of $10 \mathrm{~cm} / \mathrm{s}$ at both $14 \mathrm{dpl}$ and 28 dpl. Because our lesions were unilateral, we expected to see the greatest differences between the left limbs of the LesVeh and the LesTam groups, and this is what we observed. At 14 $\mathrm{dpl}$, the LesTam group displayed significant differences in 


\section{Articles $\mid$ Birch et al.}

left hind limb absolute paw angle compared with the LesVeh group (LesTam $22.7 \pm 4.4^{\circ}$ vs. LesVeh $14.6 \pm 4.1^{\circ}, P=0.034$; $n=3$ ShamVeh, 3 ShamTam, 2 LesVeh, and 4 LesTam mice). LesVeh mice also differed compared with ShamVeh and ShamTam mice for this parameter (LesVeh $14.6 \pm 4.1^{\circ}$ vs. ShamVeh $24.4 \pm 2.8^{\circ}, P=0.019$ and ShamTam $24.0 \pm 2.8^{\circ}$; $P=0.023$ ) (Figure 2a). We were surprised to find that the LesTam group also displayed significant differences in right hind limb paw angle variability compared with the LesVeh group (LesTam $31.3 \pm 13^{\circ}$ vs. LesVeh $69.1 \pm 35^{\circ}, P=0.033 ; n$ = 3 ShamVeh, 3 ShamTam, 2 LesVeh, and 4 LesTam mice). LesVeh mice also differed compared with ShamVeh and ShamTam mice for this parameter (LesVeh $69.1 \pm 35^{\circ}$ vs. ShamVeh $31.1 \pm 12^{\circ}, P=0.040$ and ShamTam $25.1 \pm 12^{\circ}, P=$ 0.022 ) (Figure $2 b$ ). Right hind limb changes may be compensatory for changes in left hind limb function. Together, the digital gait analysis supports the hypothesis that miRs regulated by Dicer in neural progenitors worsen the outcomes of perinatal $\mathrm{HI}$ injured mice.

When we assessed ambulation at $28 \mathrm{dpl}$, again at a speed of $10 \mathrm{~cm} / \mathrm{s}$, the LesTam group displayed significant differences in left hind limb paw area variability compared with the LesVeh group (LesTam $0.056 \mathrm{~cm}^{2} \pm 0.011 \mathrm{~cm}^{2}$ vs. LesVeh $0.04 \mathrm{~cm}^{2} \pm$ $0.010 \mathrm{~cm}^{2}, P=0.049 ; n=3$ ShamVeh, 3LesVeh, and 5LesTam) (Figure 2c). For each of these parameters, LesTam differed significantly from LesVeh animals and approximated ShamVeh animals, suggesting rescue by Dicer excision. All other limbs did not show any significant differences between LesTam and LesVeh groups at either time point.

Perinatal Hypoxia-Ischemia Increases Expression of miRs Known to Regulate OPC Differentiation

Since our experiments showed that knocking down mature miRs in OPCs in neural progenitors improved several parameters following HI, we wanted to test whether miRs known to regulate differentiation of OPCs were affected by HI. We used quantitative RT-PCR to measure four specific mature miRs: miR-9, miR-138, miR-219, and miR-338. We collected cortex and subcortical white matter at 24,48 , and $72 \mathrm{~h}$ as well as $7 \mathrm{~d}$ after injury, isolated total RNA, produced cDNA, and amplified the miRs. We found significant increases in miR-138 7 $\mathrm{d}$ after injury $(0.932 \pm 0.06)$ compared with $24 \mathrm{~h}$ after injury $(0.103 \pm 0.02, P=0.006)$ and compared with $48 \mathrm{~h}$ after injury $(0.343 \pm 0.10, P=0.04)(n=3$ for each treatment group and time point) (Figure $3 \mathrm{a}$ ). We also found significant increases in miR-338 $7 \mathrm{~d}$ after injury $(0.005 \pm 0.002)$ compared with $24 \mathrm{~h}$ after sham surgery $(0.001 \pm 0.001, P=0.008)$, and compared with $24 \mathrm{~h}$ after injury $(0.001 \pm 0.0003, P=0.004), 48 \mathrm{~h}$ after injury $(0.001 \pm 0.0003, P=0.004)$, and $72 \mathrm{~h}$ after injury $(0.001 \pm 0.0004, P=0.013)(n=3$ for each treatment group and time point) (Figure $3 \mathrm{~b}$ ). In contrast, we found no significant changes in miR-9 levels at $24 \mathrm{~h}, 48 \mathrm{~h}, 72 \mathrm{~h}$, and $7 \mathrm{~d}$ after injury. Moreover, we were unable to detect miR-219 at any of these time points. It is possible that miR-219 may not be expressed in mouse until later than $2 \mathrm{wk}$ postnatal age.

\section{DISCUSSION}

MiRs are now recognized as important regulators of gene expression during cell differentiation, even in fully mature organisms. Indeed, the expression of certain genes is more dependent on levels of miRs than on mRNAs (12). Greater than one-third of all human genes are predicted to be regulated by miRs (13). Genes unique to the brain and oligodendroglial genes in particular are no exception.

Production of functional miRs is a complex multistep process. The dsRNA nuclease Dicer is essential to this process. It cleaves premature miRs to form 10-25 nucleotide doublestranded mature miRs. Next, mature miRs complex with RNA Induced Silencing Complex/Argonaute and suppress protein translation by binding to the 3'UTR of mRNA, inhibiting translation or marking translated mRNA for degradation (4). Thus, since Dicer is involved in the initial step in the production of

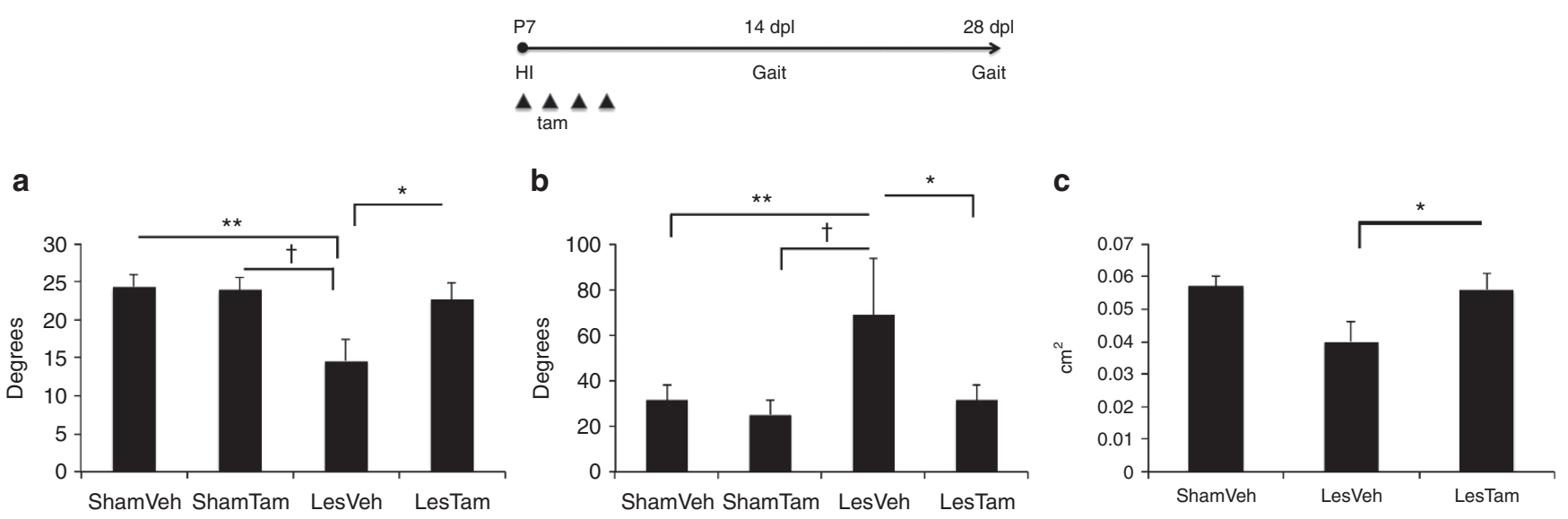

Figure 2. Loss of Dicer in NG2 expressing cells following hypoxia-ischemia results in improved parameters of ambulation at 14 and $28 \mathrm{~d}$ after injury. Timeline of experimental procedure (dpl, days post lesion; Hl, hypoxia-ischemia; Gait, digital gait analysis; P, postnatal day; tam, tamoxifen). (a) Absolute paw angle. Quantification of absolute paw angle at left hind limb at $14 \mathrm{dpl}$. Error bars $=\mathrm{SD}$. ${ }^{*} P=0.034 ;{ }^{* *} P=0.0192 ;{ }^{+} P=0.023 ; n=3$ ShamVeh, 3 ShamTam, 2 LesVeh, and 4 LesTam mice. (b) Paw angle variability. Quantification of paw angle variability at right hind limb at $14 \mathrm{dpl}$. Error bars $=$ SD. ${ }^{*} P=$ $0.033 ;{ }^{* *} P=0.040 ;{ }^{\dagger} P=0.022 ; n=3$ ShamVeh, 3 ShamTam, 2 LesVeh, and 4 LesTam mice. (c) Paw area variability. Quantification of paw area variability at left hind limb $28 \mathrm{dpl}$. Error bars $=$ SD. ${ }^{*} P=0.049 ; n=3$ ShamVeh, 3 LesVeh, and 5 LesTam mice. 

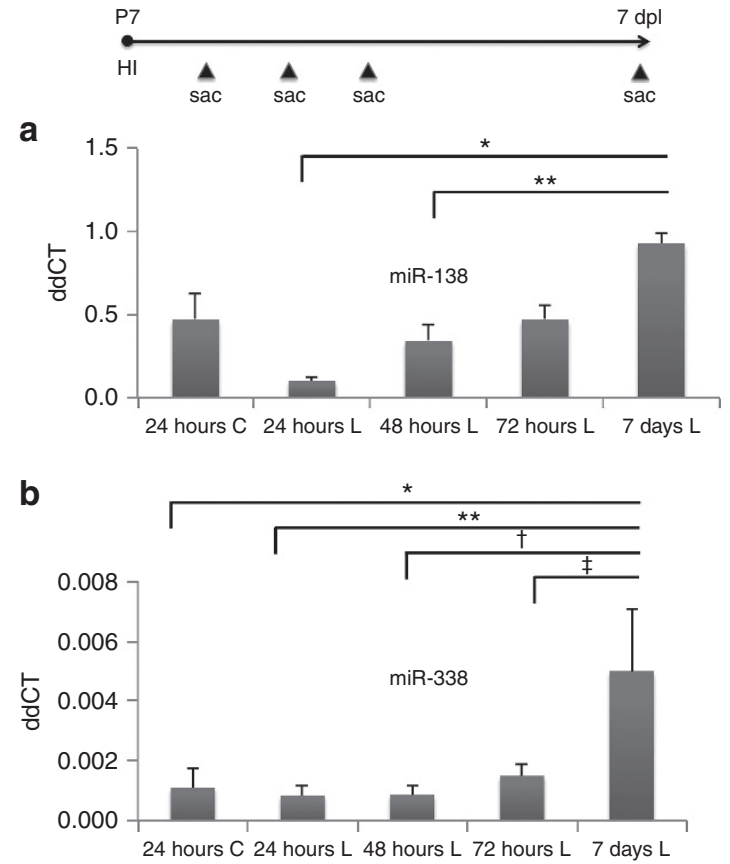

Figure 3. Hypoxia-ischemia in wild-type mice increases expression of microRNAs known to regulate differentiation of oligodendrocyte progenitor cells. Timeline of experimental procedure (dpl, days post lesion; $\mathrm{HI}$, hypoxia-ischemia; P, postnatal day; sac, sacrifice). (a) Quantification of miR-138 (C, control; ddCT, delta delta cycle time; $L$, lesion; miR, microRNA). Error bars $=$ SEM. ${ }^{*} P=0.006 ;{ }^{* *} P=0.04 ; n=3$ for each treatment group and time point. (b) Quantification of miR-338. ${ }^{*} P=0.008 ;{ }^{* *} P=0.004 ;{ }^{\dagger} P=$ $0.004 ;{ }^{\ddagger} P=0.013 ; n=3$ for each treatment group and time point.

mature miRs, excision of Dicer is an effective strategy to prevent the function of mature miRs generally.

Because complete loss of function of Dicer is embryonic lethal, conditional knockdown is required (7). Telencephalonspecific Dicer mutants have implicated miRs as important in brain development (4). The Nestin-CreER;Dicer ${ }^{\mathrm{f} / \mathrm{fl}}$ mouse, in which Dicer is deleted in radial glia, displays embryonic lethality whereas the Emx1-Cre;Dicer ${ }^{\mathrm{A} / \mathrm{ll}}$ mouse, in which Dicer is deleted at a later developmental stage, survives until postnatal day 30. Nestin-Cre;Dicer ${ }^{\mathrm{A} / \mathrm{l} /}$ mice have thinner cortices, smaller ventricular and subventricular zones, and a thin cortical plate at E18.5 compared with wild type, implicating Dicer in the regulation of neural stem cell proliferation. Emx-1Cre;Dicer ${ }^{\mathrm{f} / \mathrm{fl}}$ mice similarly have thinner cortices and smaller ventricular and intermediate zones, but in contrast have an enlarged cortical plate and no detectable hippocampus at E17.5, additionally implicating Dicer in the regulation of early neural stem cell differentiation (6).

MiRs in general continue to be important after commitment of neural progenitors to the oligodendroglial lineage, as evidenced by delayed myelination in Olig2Cre;Dicer ${ }^{\mathrm{n} / \mathrm{fl}}$ and CNPaseCre;Dicer ${ }^{\mathrm{f} / \mathrm{fl}}$ mice (8), decreased myelin in Olig1Cre;Dicer ${ }^{\mathrm{f} / \mathrm{fl}}$ mice (9), and dysmyelination in PLPCre; Dicer $^{\mathrm{f} / \mathrm{fl}}$ mice (10). Furthermore, mature OLs are decreased in Olig2Cre;Dicer ${ }^{\mathrm{f} / \mathrm{fl}}$ mice but not in CNPaseCre;Dicer ${ }^{\mathrm{f} / \mathrm{fl}}$ mice (8). Interestingly, the effects of lost Dicer in both Olig2Cre; Dicer $^{\mathrm{f} / \mathrm{fl}}$ and CNPaseCre;Dicer ${ }^{\mathrm{f} / \mathrm{fl}}$ mice are cell autonomous
(8). This is in contrast to the GFAPCre; Dicer $^{\mathrm{A} / \mathrm{fl}}$ mouse in which non-cell-autonomous effects result in the death of neurons (14). In the peripheral nervous system, mature miRs are required for maturation of Schwann cells as evidenced by the lack of mature myelin in DhhCre;Dicer ${ }^{\mathrm{f} / 1 / 1}$ mice $(15,16)$ and POCre;Dicer ${ }^{\mathrm{A} / \mathrm{l}}$ mice (17). In vitro, Schwann cells transduced with lentiviral vector encoding shRNA to Dicer also fail to myelinate cocultured dorsal root ganglion neurons (18).

None of these studies tested the effect of knocking down Dicer in a disease or injury state. In particular, no studies to date address the role of Dicer within the context of perinatal HI. Ours is the first study to show that mature miRs in general suppress a regenerative oligodendroglial response to perinatal HI. We showed that if Dicer is knocked down specifically within OPCs following perinatal HI, NG2CreER ${ }^{\mathrm{T} 2}$; Dicer $^{\mathrm{A} / \mathrm{fl}}$ mice fared better in terms of quantity of mature oligodendrocytes, quality of myelin, and measurable parameters of ambulation. Because Dicer knockdown would prevent the production of all mature miRs, the effect we observed suggests that the net effect of all mature miRs induced by perinatal HI is to suppress the production of mature oligodendroglia. Our experiments suggest that mature miRs induced by perinatal HI may decrease the maturation rate of immature OLs into mature OLs; furthermore, they may decrease the differentiation rate of OPCs into OLs; alternatively, they may increase the proliferation rate of OPCs at the expense of differentiation.

Beyond Dicer knockouts, specific miRs have been identified as important regulators of neural stem cells. Following commitment of neural stem cells to the oligodendroglial lineage, specific miRs have been implicated in regulation of further differentiation. Lau et al. (19) performed microarray analysis on fluorescence-activated cell sorting (FACS) sorts of A2B5+GalC - cells from rat brain, compared them with FACS sorts of A2B5-GalC+ cells, and showed, in combination with other published microarray studies, that at least $38 \mathrm{miRs}$ are uniquely expressed in OLs but not neurons or astrocytes. From their microarray analysis, they found that miR-9 was significantly downregulated during OPC differentiation. They examined miR-9 expression and the expression of its predicted target PMP22 mRNA and PMP22 protein and showed a negative target bias relationship in both OLs centrally and Schwann cells peripherally. In addition, their microarray analysis showed preferential expression of miR-338 in differentiating OLs (19). Zhao et al. (9), in their microarray study of Olig1Cre;Dicer ${ }^{\mathrm{n} / \mathrm{fl}}$ mice and Olig1 null mice, found miR-338 and miR-219 to be significantly downregulated in their myelin-deficient mutants. Dugas et al. (8) showed that miR-219 and miR-138 were induced when OPC cultures were differentiated through microarray studies of rat OPCs cultured in $\mathrm{PDGF}+/ \mathrm{T} 3-$ media compared with OPCs cultured in PDGF-/T3+ media. Thus, several miRs have been implicated in oligodendroglial differentiation, but only four specific miRs have been well validated.

None of these studies evaluated the expression of specific oligodendroglia-regulating miRs in the context of a CNS disease state. One study that did identify specific miRs in the context of a CNS disease state modeled fetal ethanol exposure 


\section{Articles $\mid$ Birch et al.}

using human fetal neurospheres to explore miR-mediated effects on neural stem/progenitor cells. Ethanol at high levels suppressed miR-21 and miR-335, but ethanol at lower levels increased miR-335. Knockdown of miR-21 resulted in apoptosis whereas knockdown of miR-335 resulted in cell proliferation and blockade of the miR-21 knockdown-mediated apoptosis. Moreover, miR-335 was downregulated during OL differentiation whereas miR-21 was upregulated. These results suggest antagonistic actions of select $\mathrm{miR}$ on neural progenitor differentiation (20). Another study modeled perinatal HI using primary neuronal cultures and primary astrocyte cultures from fetal rats subjected to oxygen-glucose deprivation (OGD) to examine changes in specific miRs. This study found that in neurons, miR-29b was upregulated starting $6 \mathrm{~h}$ after OGD, peaking at $24 \mathrm{~h}$ after OGD, and miR-21 was upregulated $24 \mathrm{~h}$ after OGD. Similarly in astrocytes, miR-29b and miR-21 were both upregulated $12 \mathrm{~h}$ after OGD (21). Specific miRs have been studied in models of adult brain ischemia. Jeyaseelan et al. (22) performed miR microarrays on the blood and brain of adult rats after transient middle cerebral artery occlusion (MCAO) and found that miR-124a and miR-223 were highly expressed 24 and $48 \mathrm{~h}$ after injury. Dharap et al. (23), who also used microarray and the same injury model, identified miR145 as highly expressed between $3 \mathrm{~h}$ and $3 \mathrm{~d}$ after injury. Liu et al. (24) used a permanent MCAO model as well as models of intracerebral hemorrhage and kainate-induced seizures and found that miR-298 is upregulated in blood and brain across all three injury models. None of these studies addressed miRs regulating the oligodendroglial lineage specifically.

Ours is the first study to show in an in vivo disease model of perinatal $\mathrm{HI}$ that specific miRs are altered, namely that miR-138 and miR-338 were specifically upregulated. We have also observed that miR-21 is significantly upregulated $72 \mathrm{~h}$ after injury (data not shown). It would be interesting to explore whether miR-138, miR-21, or miR-338 were part of the mechanism leading to blocked maturation of OPCs seen after perinatal HI. Indeed, loss of Dicer in DhhCre;Dicer/f/f mice led to the proliferation of immature Schwann cells (15). We speculate that a precise temporal knockdown of miRs specifically regulating OPC differentiation might prevent white matter loss due to perinatal HI. In a first in vivo attempt to manipulate miRs after oligodendroglial development, Zhao et al. electroporated miR-338 and miR-219 expression vectors in ovo and achieved ectopic formation of OLs and precocious OL differentiation in the spinal cord; conversely, knockdown of these miRs inhibited OL maturation. Similarly, Dugas et al. (8) used miR-219 and miR-138 mimetics to promote OL differentiation and partially rescued OL in Dicer negative OPC cultures. Although these studies used miR mimetics and $\mathrm{miR}$ antisense inhibitors to evaluate normal development, none used these strategies to rescue pathology in white matter disease. Dharap et al. (23) did test whether knockdown of miR-145 effected protection following transient MCAO; they found that miR-145 antagonists resulted in increased superoxide dismutase 2 expression in peri-infarct neurons as well as decreased cortical infarct size.
It is our view that HI transiently inhibits Dicer, resulting in delayed and exuberant expression of mature miRs. In the case of perinatal HI, miR-138 and miR-338, which are normally expressed upon differentiation of OPCs to OLs, are delayed in their expression. This in turn delays their normal function of repressing promoters of OPC proliferation, namely PDGFRA, Sox6, and FoxJ3 (8). MiR-338 additionally targets ZNF238, another promoter of OPC proliferation $(8,25)$. Such an effect is consistent with observed increases in OPCs following perinatal HI $(2,3)$. A search of the bioinformatics database miRWalk shows that miR-138, miR-338, and miR-9 are all implicated in the PDGF pathway (25). Other validated targets of miR-138 include EGF, EGFR, and CCND1 (25), which are all involved in cell proliferation; this makes sense given differentiation requires decreased proliferation. Interestingly, DICER1 is a validated target common to miR-138, miR-338, and miR9, RNASEN is a validated target of miR-138 and miR-9, and AGO1 and AGO2 are validated targets of miR-9 (25). Thus, high levels of these miRs may regulate these essential components of miR processing in a negative feedback mechanism. In this way, excessively elevated levels of miR-138 and miR-338 may yield the paradoxic effect of fewer mature OLs rather than more mature OLs. Knocking down Dicer in OPCs in the days following perinatal HI may restore levels of oligodendrogliaregulating miRs closer to levels seen in normal development.

A major strength of our study is the use of a genetic model to tease out mechanisms leading to white matter injury and rescue. Moreover, by design, we induced loss of Dicer to temporally follow the injury, much the way interventions would be administered clinically. Our study was limited by the fact that we pooled Dicer heterozygous and homozygous mutants. Likely we would have observed more robust differences compared with wild-type mice in both cell counts and function by distinguishing between heterozygotes and homozygyotes. Nonetheless, we were able to show that mature miRs are required for the white matter loss that occurs following perinatal $\mathrm{HI}$ and that specific miRs are upregulated following perinatal HI. Stated otherwise, mature miRs play a role in the perturbation of oligodendroglial differentiation following perinatal HI; important candidates likely include miR-138 and miR-338. We anticipate future studies using the strategy of specific miR mimetics and specific miR inhibitors of these candidates and others to prevent white matter disease following premature birth.

\section{METHODS \\ Animals}

CD-1 mice (Charles River, Chicago, IL) were used for quantitative real-time RT-PCR experiments. NG2CreER ${ }^{\mathrm{T} 2} ;$ Dicer $^{\mathrm{fl} / \mathrm{fl}}$ mice were used for the remainder of the experiments; Dicer homozygous and heterozygous mutants were pooled and analyzed as Dicer floxed mutants. NG2CreER ${ }^{\mathrm{T} 2}$ mice were obtained from Dr Akiko Nishiyama (University of Connecticut-Storrs, CT) and crossed with the Dicer floxed mouse that was obtained with the permission of Dr Brian Harfe (University of Florida-Gainesville, FL). All mice were backcrossed to a C57Bl6 background for at least six generations. Mice were housed in a facility with a 12-h light/dark cycle and allowed access to food 
and water ad libitum. Experiments were conducted according to protocols approved by the Institutional Animal Care and Use Committee and Northwestern Center for Comparative Medicine.

\section{Neonatal Hypoxic-Ischemic Lesions}

Postnatal day 7 (P7) mice were anesthetized with isoflurane, and the right common carotid artery was ligated and transected. After $2-\mathrm{h}$ recovery, pups were placed in humidified hypoxia chambers $(8 \%$ oxygen $/ 92 \%$ balanced air) kept at $37^{\circ} \mathrm{C}$ for $45 \mathrm{~min}$ for CD-1 mice or $60 \mathrm{~min}$ for NG2CreER ${ }^{\mathrm{T} 2}$; Dicer floxed mice, were allowed to recover for $1 \mathrm{~h}$, and then returned to the dam as previously described $(26,27)$. Nonlesioned controls underwent sham surgeries. Conditional inducible mice were treated with either tamoxifen (Sigma T5648) (Sigma, St Louis, MO) $60 \mathrm{mg} / \mathrm{kg}$ dissolved in sterile corn oil:100\% ethanol (9:1) or vehicle only i.p. once daily starting after HI on P7, P8, P9, and P10.

\section{Immunofluorescence}

Mice were anesthetized with carbon dioxide, transcardially perfused with $0.9 \% \mathrm{NaCl}$ followed by $4 \%$ paraformaldehyde (PFA) in PBS, brains were removed, postfixed overnight in ice cold 4\% PFA, cryoprotected in $30 \%$ sucrose in PBS, embedded and frozen in O.C.T. Compound (Sakura Finetek 4583) (Sakura, Torrence, CA), cut into $10-\mu \mathrm{m}$ sections using a cryostat, and immunostained using the following antibodies: CNPase 1:200 (Sternberger SMI91) (Covance, Princeton, NJ), MBP 1:500 (Sternberger SMI99), Olig1 1:600 (Chemicon AB5540) (EMD Millipore, Billirica, MA), Olig2 1:400 (Chemicon AB9610), PDGFRA 1:200 (Fitzgerald CD140a) (Fitzgerald, North Acton, MA), AlexaFluor 488 Goat anti-Rabbit 1:500, AlexaFluor 594 Goat antiMouse IgG1 1:500, AlexaFluor 594 Goat anti-Mouse IgG2b 1:500, and AlexaFluor 594 Goat anti-Mouse IgM 1:500 (Invitrogen) (Life Technologies, Grand Island, NY).

\section{Histochemistry}

Frozen sections were hydrated sequentially from $70 \%$ ethanol for $30 \mathrm{~min}$ to $95 \%$ ethanol for $30 \mathrm{~min}$, then they were placed in $1 \%$ Luxol fast blue solution (Luxol fast blue $1 \mathrm{~g}$ (S3382, Sigma-Aldrich, St Louis, MO), $95 \%$ ethanol $100 \mathrm{ml}, 10 \%$ acetic acid $5 \mathrm{ml}$ ) at $60{ }^{\circ} \mathrm{C}$ for $16 \mathrm{~h}$. Slides were rinsed with $95 \%$ ethanol, then $\mathrm{ddH}_{2} \mathrm{O}$, then differentiated in $0.05 \%$ lithium carbonate solution (lithium carbonate $0.5 \mathrm{~g}$ (L4283, Sigma-Aldrich), dd $\mathrm{H}_{2} \mathrm{O} 1,000 \mathrm{ml}$ ) for $5 \mathrm{~s}$ followed by $70 \%$ ethanol for $5 \mathrm{~s}$ twice, then rinsed with $\mathrm{ddH}_{2} \mathrm{O}$. Differentiation steps were repeated until gray matter had cleared. Slides were counterstained in $0.25 \%$ cresyl echt violet solution (cresyl violet acetate (C1791, Sigma-Aldrich) $0.1 \mathrm{~g}$, dd $\mathrm{H}_{2} \mathrm{O} 100 \mathrm{ml}$, glacial acetic acid 10 drops) for $40 \mathrm{~s}$ then rinsed in $\mathrm{ddH}_{2} \mathrm{O}$ and differentiated in $95 \%$ ethanol for $5 \mathrm{~min}$, then rinsed in $100 \%$ ethanol for $5 \mathrm{~min}$ twice. Slides were dehydrated through from $95 \%$ ethanol through $100 \%$ ethanol, cleared with xylene, and coverslips were mounted with Permount (SP15-500, Fisher Scientific, Pittsburgh, PA).

\section{Quantitative RT-PCR}

Mice were anesthetized with carbon dioxide, then were decapitated, brains were removed and chilled in ice-cold PBS for $5 \mathrm{~min}$, cut into $1-\mathrm{mm}$ sections using a stainless steel mouse brain slicer, then an approximately $15 \mathrm{mg}$ piece of intact peri-infarct cortex/subcortical white matter was dissected using tungsten needles at 24,48 , and $72 \mathrm{~h}$ and $7 \mathrm{~d}$ after lesioning. Tissue was collected into PBS. Total RNA was obtained using the RNAqueous-4PCR kit (Ambion) (Life Technologies). A total of $1 \mu \mathrm{g}$ of RNA was used for generating cDNA using the Thermoscript reverse transcriptase and oligo-dT primers (Invitrogen) (Life Technologies). cDNA was stored at $-80{ }^{\circ} \mathrm{C}$ until used. Quantitative real-time PCR for mature miR-9, miR-138, and miR-338 was performed using the Taqman microRNA Assays for these mature miRs and snoRNA202 for internal controls (Taqman) (Life Technologies). A total of $1 \mu \mathrm{l}$ of $\mathrm{cDNA}$ was used per PCR. The following cycling parameters were used: $95^{\circ} \mathrm{C} \times 10 \mathrm{~min}$, for 40 cycles, $95^{\circ} \mathrm{C} \times 15 \mathrm{~s}, 60^{\circ} \mathrm{C} \times 1 \mathrm{~min}$.

\section{Digital Gait Analysis}

Digital video images of the underside of mice walking at a speed of $10 \mathrm{~cm} / \mathrm{s}$ were collected and analyzed using the DigiGait Imaging System and software (Mouse Specifics, Boston, MA) as previously described (28). Mouse paw area over time was used to calculate various parameters of gait. The results of lesioned animals that received tamoxifen were compared with the results of lesioned animals that received vehicle.

\section{Statistics and Analysis}

Two to five mice were used per treatment group. Mid-striatal coronal sections were collected (between $+0.98 \mathrm{~mm}$ anterior to Bregma and +0.38 posterior to Bregma). For each animal, four $40 \times$ fields were captured from the corpus callosum and the supracallosal radiations, using Axiovision 4.6 software (Carl Zeiss Vision, Thornwood, NY). Image files were encoded to mask the study group, areas were measured, and cells were counted using Axiovision 4.6 and Image J software (NIH) by investigators blinded to group. After counts were completed, the data were decoded and cell counts per area were calculated for each field and averaged. Relative fluorescence was measured using Metamorph software (Molecular Devices, Sunnyvale, $\mathrm{CA}$ ). Integrated density was measured using ImageJ (NIH, Bethesda, $\mathrm{MD})$. Two group comparisons (cell counts and relative expression) were analyzed by the Student's $t$-test and the significance level was set at $P<0.05$. Four group comparisons were analyzed by ANOVA, using Fisher's PLSD for post hoc comparisons with statistical significance set at $P<0.05$.

\section{SUPPLEMENTARY MATERIAL}

Supplementary material is linked to the online version of the paper at http://www.nature.com/pr

\section{ACKNOWLEDGMENTS}

This work was supported by the Northwestern University Behavioral Phenotyping Core.

\section{STATEMENT OF FINANCIAL SUPPORT}

This work was supported by the National Institutes of Health (NIH), National Institute of Neurological Disorders and Stroke (NINDS), Bethesda, MD, USA, grants 5K08 NS053529, NS20778-28, and NS20013-29.

\section{REFERENCES}

1. Back SA, Luo NL, Borenstein NS, Levine JM, Volpe JJ, Kinney HC. Late oligodendrocyte progenitors coincide with the developmental window of vulnerability for human perinatal white matter injury. J Neurosci 2001;21:1302-12.

2. Dizon M, Szele F, Kessler JA. Hypoxia-ischemia induces an endogenous reparative response by local neural progenitors in the postnatal mouse telencephalon. Dev Neurosci 2010;32:173-83.

3. Segovia KN, McClure M, Moravec M, et al. Arrested oligodendrocyte lineage maturation in chronic perinatal white matter injury. Ann Neurol 2008;63:520-30.

4. Stefani G, Slack FJ. Small non-coding RNAs in animal development. Nat Rev Mol Cell Biol 2008;9:219-30.

5. Yi R, Fuchs E. A miR image of stem cells and their lineages. Curr Top Dev Biol 2012;99:175-99.

6. Kawase-Koga Y, Otaegi G, Sun T. Different timings of Dicer deletion affect neurogenesis and gliogenesis in the developing mouse central nervous system. Dev Dyn 2009;238:2800-12.

7. Petri R, Malmevik J, Fasching L, Åkerblom M, Jakobsson J. miRNAs in brain development. Exp Cell Res 2014;321:84-9.

8. Dugas JC, Cuellar TL, Scholze A, et al. Dicer1 and miR-219 are required for normal oligodendrocyte differentiation and myelination. Neuron 2010;65:597-611.

9. Zhao X, He X, Han X, et al. MicroRNA-mediated control of oligodendrocyte differentiation. Neuron 2010;65:612-26.

10. Shin D, Shin JY, McManus MT, Ptácek LJ, Fu YH. Dicer ablation in oligodendrocytes provokes neuronal impairment in mice. Ann Neurol 2009;66:843-57.

11. Zhu X, Hill RA, Dietrich D, Komitova M, Suzuki R, Nishiyama A. Agedependent fate and lineage restriction of single NG2 cells. Development 2011;138:745-53.

12. Johnson CD, Esquela-Kerscher A, Stefani G, et al. The let-7 microRNA represses cell proliferation pathways in human cells. Cancer Res 2007;67:7713-22. 
13. Lewis BP, Burge CB, Bartel DP. Conserved seed pairing, often flanked by adenosines, indicates that thousands of human genes are microRNA targets. Cell 2005;120:15-20.

14. Tao J, Wu H, Lin Q, et al. Deletion of astroglial Dicer causes non-cell-autonomous neuronal dysfunction and degeneration. J Neurosci 2011;31:830619.

15. Bremer J, O'Connor T, Tiberi C, Rehrauer H, Weis J, Aguzzi A. Ablation of Dicer from murine Schwann cells increases their proliferation while blocking myelination. PLoS One 2010;5:e12450.

16. Pereira JA, Baumann R, Norrmén C, et al. Dicer in Schwann cells is required for myelination and axonal integrity. J Neurosci 2010;30:6763-75.

17. Yun B, Anderegg A, Menichella D, Wrabetz L, Feltri ML, Awatramani R. MicroRNA-deficient Schwann cells display congenital hypomyelination. J Neurosci 2010;30:7722-8.

18. Verrier JD, Semple-Rowland S, Madorsky I, Papin JE, Notterpek L. Reduction of Dicer impairs Schwann cell differentiation and myelination. J Neurosci Res 2010;88:2558-68.

19. Lau P, Verrier JD, Nielsen JA, Johnson KR, Notterpek L, Hudson LD. Identification of dynamically regulated microRNA and mRNA networks in developing oligodendrocytes. J Neurosci 2008;28:11720-30.

20. Sathyan P, Golden HB, Miranda RC. Competing interactions between micro-RNAs determine neural progenitor survival and proliferation after ethanol exposure: evidence from an ex vivo model of the fetal cerebral cortical neuroepithelium. J Neurosci 2007;27:8546-57.
21. Ziu M, Fletcher L, Rana S, Jimenez DF, Digicaylioglu M. Temporal differences in microRNA expression patterns in astrocytes and neurons after ischemic injury. PLoS One 2011;6:e14724.

22. Jeyaseelan K, Lim KY, Armugam A. MicroRNA expression in the blood and brain of rats subjected to transient focal ischemia by middle cerebral artery occlusion. Stroke 2008;39:959-66.

23. Dharap A, Bowen K, Place R, Li LC, Vemuganti R. Transient focal ischemia induces extensive temporal changes in rat cerebral microRNAome. J Cereb Blood Flow Metab 2009;29:675-87.

24. Liu DZ, Tian Y, Ander BP, et al. Brain and blood microRNA expression profiling of ischemic stroke, intracerebral hemorrhage, and kainate seizures. J Cereb Blood Flow Metab 2010;30:92-101.

25. Dweep H, Sticht C, Pandey P, Gretz N. miRWalk-database: prediction of possible miRNA binding sites by "walking" the genes of three genomes. J Biomed Inform 2011;44:839-47.

26. Ditelberg JS, Sheldon RA, Epstein CJ, Ferriero DM. Brain injury after perinatal hypoxia-ischemia is exacerbated in copper/zinc superoxide dismutase transgenic mice. Pediatr Res 1996;39:204-8.

27. Plane JM, Liu R, Wang TW, Silverstein FS, Parent JM. Neonatal hypoxicischemic injury increases forebrain subventricular zone neurogenesis in the mouse. Neurobiol Dis 2004;16:585-95.

28. Hampton TG, Stasko MR, Kale A, Amende I, Costa AC. Gait dynamics in trisomic mice: quantitative neurological traits of Down syndrome. Physiol Behav 2004;82:381-9. 